\title{
Back to the Origins of the Initial Public Offerings Price Range: Underwriter-Funds Network and Information Production Timeline
}

\author{
Camilla Mazzoli ${ }^{1}$, Claudia Pigini ${ }^{1} \&$ Sabrina Severini ${ }^{1}$ \\ ${ }^{1}$ Università Politecnica delle Marche, Piazzale Martelli 8, Ancona, Italy \\ Correspondence: Camilla Mazzoli, Department of Management, Università Politecnica delle Marche, Piazzale \\ Martelli 8, 60121 Ancona, Italy. Tel: 039-071-220-7254. E-mail: c.mazzoli@ univpm.it
}

Received: September 8, 2020

Accepted: October 13, 2020

Online Published: October 20, 2020

doi:10.5539/ijef.v12n11p91

URL: https://doi.org/10.5539/ijef.v12n11p91

\begin{abstract}
Although the initial price range in U.S. Initial Public Offerings (IPOs) is constrained by SEC regulations, a non-negligible percentage of IPO price ranges falls outside the 'safe harbour'. We investigate how the price range - which sends the very first signals on the IPO quality to the market - is set in the due diligence phase, with special attention to unexplored networking patterns between underwriters and institutional investors. By making use of a Mixture Model applied to 1,246 US firms listed between 2004 and 2016, we show that underwriters that are centrally positioned in their network of regular investors are more likely to set a price range that is compliant with SEC guidelines. We argue that the flexibility resulting from being safe harbour-compliant allows underwriters to preserve their reputation for fair dealing with issuers by exploiting a dumping ground proviso or quid pro quo agreements with their network funds. Despite information produced by network funds in the due diligence step having no significant effect on the width of the price range, in our study, we provide evidence that the range does serve as a proxy of the uncertainty of the listing firms.
\end{abstract}

Keywords: initial public offerings, primary market pricing, interactions, network analysis, investor attention

\section{Introduction}

Although there is a substantial body of literature on the Initial Public Offering (IPO) process, unresolved questions remain on how IPOs are priced (Hanley \& Hoberg, 2010). The price at which an IPO is offered to investors is the result of information, interactions, and negotiations which unfold over the entire IPO primary market: once the underwriting syndicate has been designated, underwriters and the issuing firm conduct due diligence to draft an initial prospectus, which is filed with the SEC, and set the initial price range. Bookbuilding activities then begin, aimed at setting the final offer price based on information gathered from investors regarding their expectations in terms of the IPO secondary market success.

Previous literature has consistently identified the price range as a proxy for the uncertainty surrounding a firm's quality and/or for the firm's demand shares, quantifying a greater uncertainty with a wider price range (Butler \& Wan, 2005; Bajo, Chemmanur, Simonyan, \& Tehranian, 2016); nonetheless, no empirical investigation has unveiled the determinants of the width of the IPO price range. One reason for this lack of interest from the scientific community could be connected to the general principles provided by the U.S. Securities and Exchange Commission (SEC) that influence the setting of the price range in the preliminary prospectus. According to Item 501(b)(3) of SEC Regulation S-K, the price range must reflect a "bona fide estimate" of the final offering price, leaving space for multiple interpretations about how wide the range of the estimated offer price should be. SEC guidance provides a 'safe harbour' for issuers who limit their price range to within $\$ 2$ or to a designated percentage (Note 1). If the safe harbour threshold is not exceeded, Rule $430 \mathrm{~A}(\mathrm{a})$ enables underwriters and issuers to have some level of flexibility on pricing, allowing them to revise the deal size and /or the price range without filing a pre-effective amendment. Until an IPO registration statement has been declared effective by the SEC, it is possible to file a pre-effective amendment with a new price range and/or a new number of shares to be sold. However, using a pre-effective amendment to upsize or downsize a deal after the price range prospectus has been distributed to investors can have unwelcome timing implications (Note 2); in addition, the new filing containing the amended price range could send a signal to the market about pricing that may be premature. In this framework, by keeping the price range within the safe harbour, underwriters can revise the price range and the deal size when they are "testing the water" without having to go back to the SEC and without filing a 
pre-effective amendment. This offers a critical advantage considering that the 1933 Securities Act discourages any contact with investors during the pre-filing period and that underwriters can estimate the demand curve only after the initial prospectus, containing the price range, has been filed with the SEC.

Although the initial price range of IPOs in the U.S. is clearly constrained by regulations (Jenkinson, 2006), it is fairly evident that a non-negligible percentage of them falls outside the safe harbour (around 19\% in our sample). This evidence leaves room for research on how the price range is set and why, in some cases, underwriters are not compliant with SEC dispositions.

This paper contributes to the existing literature on IPO pricing by delving into the mechanisms behind IPO price range setting in the due diligence step. A deep understanding of these drivers is of great interest in the IPO pricing process: by managing the price range width, issuers and underwriters send the very first signals about the quality of the IPO to investors. Although previous studies have traditionally considered the IPO price range as the first indicator of quality, none have conducted an in-depth investigation into the origins of the range, especially in accordance with IPO regulations. This is the first contribution of the present work. As a second contribution, we add to the growing body of literature on Social Network Analysis (SNA) by investigating to what extent the previously unexplored networking patterns between underwriters and institutional investors affects the way information production might be incorporated into the price range setting phase. With this analysis we would thus add to the debate on the timeline of information production and/or revelation (Lowry, Michaely, \& Volkova, 2017) by testing whether repeated interactions between underwriters and investors are likely to produce information in the early primary market so as to affect the width of the price range. As a correlated contribution, we investigate the magnitude of the range as an indicator of the level of predictability regarding a firm's quality and/or the firm's demand shares, unveiling which factors might contribute to its width.

Based on a sample of 1,246 US IPOs listed on the NASDAQ and NYSE between January 2004 and December 2016, we model the width of the price range as a Mixture of a binary and a continuous variable, where the former reveals whether the price is set in compliance with the safe harbour or not, while the latter identifies the distribution of the range. This mixture is determined by the sample distribution of the price range, which presents a frequency mass within $\$ 2$. This model allows us to identify and test which factors influence the probability that IPO price ranges are set outside the safe harbour and to explain the width of the IPO range, leaving open the possibility that different drivers might account for the two measures.

In particular, our attention is focused on the previously unexplored underwriter-investor network, in terms of negative vs positive effects. For years, regulatory provisions have been designed to mitigate potential conflicts of interest arising from such networks; in contrast, information revelation theories suggest possible concurrent benefits in terms of uncertainty mitigation (Jenkinson, Jones, \& Suntheim, 2018).

Our findings reveal that IPOs underwritten by book managers with more centralized investor networks show a higher probability of setting the price range within the safe harbour. We argue that, although some flexibility in the deal size is appreciated in every new listing (in order to discreetly adapt the IPO conditions to the demand and to preserve the underwriter's reputation for dealing fairly with issuers), when a network of pre-existing relationships with institutional investors is in place, such flexibility is even more highly appreciated. In other words, if IPO conditions have to be adjusted downward based on the information coming from the bookbuilding, network funds might enable the implementation of that flexibility, thus allowing underwriters to dump shares in exchange for quid pro quos in future hot issues.

We also find that when the width of the range is analysed, it is the firm's profile, more than investors' networks, that has the greater effect on the range. This suggests that, although information production and/or revelation might already take place in the due diligence phase through a network of pre-existing relationships with institutional investors, the information that informally circulates at this time does not produce any significant effect on the width of the price range; the characteristics of the issuing firm and the IPO exert a stronger influence. Finally, we provide evidence that the width of the range serves as a proxy of the uncertainty of the listing firms, as argued by previous literature, especially in terms of size, age, and sector.

The rest of the paper is organized as follows: in Section 2 we review the literature and present our hypotheses; in Section 3 we report the data and methodology adopted in the empirical analyses and in Section 4 we discuss our key findings; Section 5 concludes the paper.

\section{Literature Review and Hypotheses}

An IPO valuation typically occurs in the form of a price range (Note 3). When firms decide to issue equity securities in public markets for the first time, underwriters and companies distribute to potential IPO investors a 
so-called red herring prospectus. This preliminary document submitted to the SEC shows the number of shares expected to be sold and a bona fide estimate of the price range per share, as required by Regulation S-K Item 501(b)(3). The SEC guidelines generally suggest no more than a $\$ 2$ difference or a designated percentage of the high-end of the range as a bona fide price range. There is a minimum period of 20 days between the filing of the prospectus and the sale of the issue. During these marketing campaign days, known as the road show, company managers and underwriters get a better sense of the demand for the IPO through nonbinding indications of interest received from regular investors (Ritter \& Welch, 2002). As a matter of the fact, following the 1933 Securities Act, potential investors are only asked to disclose their opinions about the IPO once the registration statement, including an initial indicative price range, has been filed (Jenkinson, Morrison, \& Wilhelm, 2006). However, Rule $430 \mathrm{~A}$ (a) states that, if the safe harbour threshold is not exceeded, changes in price and deal size during bookbuilding will be deemed part of the registration statement when it becomes effective. Such flexibility gives underwriters a critical advantage as it allows them to change the size or pricing of deals without having to go back to the SEC and formally asking for a pre-effective amendment. There is the added benefit of preserving the bank's reputation, as well. The central role played by underwriters in their network makes the safe harbour even more exploitable, as the adjusted IPO conditions can be more easily applied through either quid pro quo or dumping ground agreements with regular funds, depending on the specific scenario in question. In fact, some studies have demonstrated this underwriter practice of using affiliated funds as a dumping ground (Johnson \& Marietta-Westberg, 2009; Hao \& Yan, 2012), suggesting that when an unfavourable demand affects the IPO results, flexibility in the safe harbour rule allows underwriters to change the IPO conditions and dump shares in their funds without any formal amendment procedure. Other research has revealed the occurrence of quid pro quo agreements in which institutional investors who provide more informative orders get larger underpriced allocations (Reuter, 2006; Jenkinson et al., 2018). If this is the case, when favourable demand affects the IPO, flexibility in the safe harbour rule again allows underwriter to change the IPO conditions and favour its network funds.

Thus, we formulate the following hypothesis:

H(1): IPOs underwritten by book managers with more central investor networks are associated with a higher probability that their price range is set within the safe harbour.

Much of the existing research has examined whether and how the characteristics of underwriting networks (Corwin \& Schultz, 2005; Chuluun, 2015; Bajo et al., 2016; Xiaohan \& Liu, 2016; Rumokoy, Neupane, Chung, \& Vithanag, 2017) affect IPO pricing. However, the impact of investor networks on IPO pricing has not been explicitly examined (Note 4) (Rumokoy et al., 2017). It is safe to argue that the existence of a network of relationships between underwriters and regular investors can be useful in terms of forming a view on valuation, thus enabling underwriters to gather more precise information even before the roadshow begins, during the due diligence step. However, there is mixed evidence regarding the moment when information is potentially produced and revealed. While most bookbuilding theories identify the bookbuilding phase as the moment when demand and interest from institutional investors is revealed (Benveniste \& Spindt, 1989), others such as the one posited by Hanley and Hoberg (2010) open up the possibility of information production during the due diligence phase as well. In particular, it is suggested that the initial price range already contains valuable information regarding the firm's intrinsic value, as a result of talks between various players involved in the evaluation phase (management, suppliers, venture capitalists etc.). In the present study we contribute to the debate regarding the timeline of information production and/or revelation; we investigate whether the information that might circulate - through an investor network - before the bookbuilding phase is directly reflected in the width of the price range. Indeed, it is reasonable to argue that when underwriters have stronger relationships with their best clients, i.e., those who participate more frequently in their network, more information is revealed. In other words, we test to see if networks of underwriters and institutional investors effectively help evaluate and incorporate information into the IPO price range, thereby reducing the level of uncertainty in the initial phase. Specifically, we test the following hypothesis:

H(2): IPOs underwritten by book managers with more central investor networks are associated with a narrower width of the initial filing price range.

To the best of our knowledge, despite the width of the range being used in several studies as a proxy for IPO uncertainty and firm value, no empirical model has been proposed to investigate the drivers of the IPO range setting (Note 5). In the present study, we consider the characteristics of the bank-institutional investor network as well as the characteristics of the IPO and/or the issuing firms as possible factors that might affect range width.

Our paper differs from Chuluun (2015) and Bajo et al. (2016) on several fronts. First, these studies examine the 
location of a lead underwriter in its network of investment banks; as a result, they investigate how, through these relationships, an underwriter can tap into other underwriters' client and investor networks indirectly. By contrast, our paper more directly investigates underwriter-institutional investor relationships. Second, Chuluun (2015) and Bajo et al. (2016) analyze the impact of underwriter peer networks on IPO secondary market pricing and performance, while our paper focuses on the IPO primary market, analysing the effects of the network of investors on the first pricing information: the price range.

\section{Data and Methods}

\subsection{Sample Selection}

We collected our sample of U.S. IPOs from the Thomson One Deals database (TOD). We searched for all the IPOs occurring from January 2004 to December 2016, on the NASDAQ and NYSE. We then excluded IPOs with any of the following characteristics (as previously suggested by Ritter \& Zhang, 2007): offer price below $\$ 5$ (Note 6), non-common shares, closed-end funds, filings by foreign-domiciled firms, Master Limited Partnerships (MLPs), American Depository Receipts (ADRs), and Real Estate Investment Trusts (REITs). The final sample consisted of 1,246 IPOs. In order to build the network and to observe the relationships that occurred between institutional investors and underwriters, we collected the lead managers' names from the TOD and the data on institutional investor participation in $13 \mathrm{~F}$ institutional ownership. However, information regarding actual allocation and, consequently, participation in the offer is not publicly available. Therefore, as many of previous authors did, we made use of the first reported holding by investors at the end of the offering quarter as a proxy for participation in the IPO (Reuter, 2006; Ritter \& Zhang, 2007; Field \& Lowry, 2009; Goyal \& Tam, 2013). We also included information regarding issuing firms' financial statements, as obtained from Compustat (Note 7). The Jay Ritter website was also used to obtain information regarding market conditions and the rankings of U.S. underwriters based on their reputation.

\subsection{Methodology}

In order to build a statistical model for the determinants of how the price range is set, we consider the range width as a mixture of a binary and a continuous variable, given that approximately $76 \%$ of the IPOs in our sample are priced within a $\$ 2$ range. In this setting, the discrete binary variable describes whether the price is set in compliance with SEC guidelines or not, whereas the continuous variable informs on the distribution of the range. Hence, we set up a Mixture Model that allows us to explore the determinants of the likelihood of setting an IPO range outside the SEC parameters and of the width of the price range. It is worth underscoring that, to the best of our knowledge, this is a first attempt at investigating the determinants of an IPO's price range. Although the Mixture Model has been used to describe other phenomena such as IPO returns (Asquith, Jones \& Kieschnick, 1998; Escobari \& Serrano, 2015), there is no previous theoretical background driving the decision to use a Mixture Model for the width of the price range. In fact, this modelling choice was based on the sample distribution of the price range; indeed, it allowed us to identify potentially different drivers for the probability that IPO price ranges are set outside the safe harbour and for the width of the IPO range.

For a sample of $T$ IPOs, let the response variable $\mathrm{Y}_{\mathrm{t}}$ be the width of the range (high filing price - low filing price) for the $t$-th IPO, with $t=1, \ldots, T$. In order to model the probability of setting an IPO range outside the SEC guidelines, we consider a width greater than $\$ 2$. We use the $\$ 2$ target value because it has not changed over time (see Note 1 for further details). Moreover, let $Z_{\mathrm{t}}$ be a vector collecting IPO characteristics, investors' attention, and the centrality measure relative to the $t$-th IPO. The response variable and covariates are described in detail in the next section.

A Mixture Model composed of three parts is adopted for the response variable $Y_{t}$, with the first component representing the probability of setting a price range greater than $\$ 2$ and the other two being two normal densities for the width, which we model separately according to whether the response variable is greater or smaller than $\$ 2$. We assume that the conditional distribution of $Y_{t}$ is

$$
f\left(Y_{t} \mid Z_{t}\right)=\begin{gathered}
{\left[1-\Lambda\left(Z_{t}^{\prime} \gamma\right)\right] \Phi\left(Y_{t} ; Z_{t}^{\prime} \beta_{I}, \sigma_{I}^{2}\right), \text { if } Y_{t} \leq \$ 2} \\
\left.\Lambda\left(Z_{t}^{\prime} \gamma\right)\right] \Phi\left(Y_{t} ; Z_{t}^{\prime} \beta_{0}, \sigma_{0}^{2}\right), \text { if } Y_{t}>\$ 2
\end{gathered}
$$

with

$$
\Lambda\left(Z_{t}^{\prime} \gamma\right)=\frac{\exp \left(z_{t}^{\prime} \gamma\right)}{1+\left(z_{t}^{\prime} \gamma\right)^{\prime}}
$$

and where $\Phi\left(Y_{t} ; Z_{t}^{\prime} \beta_{I}, \sigma_{I}^{2}\right)$ and $\Phi\left(Y_{t} ; Z_{t}^{\prime} \beta_{0}, \sigma_{0}^{2}\right)$ denote the density of the normal distributions with conditional means $Z_{t}^{\prime} \beta_{\mathrm{I}}, Z_{t}^{\prime} \beta_{0}$ and variances $\sigma_{I}^{2}, \sigma_{0}^{2}$ ) for the width smaller and greater than $\$ 2$, respectively. The model log-likelihood is then 


$$
I(\Psi)=\sum_{t=1}^{[T]}\left[1-\Lambda\left(Z_{t}^{\prime} \gamma\right)\right] \Phi\left(\mathrm{Y}_{\mathrm{t}} ; Z_{t}^{\prime} \beta_{I}, \sigma_{I}^{2}\right)^{I\left(\mathrm{Y}_{\mathrm{t}} \leq \$ 2\right)} \Lambda\left(Z_{t}^{\prime} \gamma\right) \Phi\left(\mathrm{Y}_{\mathrm{t}} ; Z_{t}^{\prime} \beta_{0}, \sigma_{0}^{2}\right)^{I\left(\mathrm{Y}_{\mathrm{t}}>\$ 2\right)}
$$

where $\mathrm{I}($.$) is an indicator function returning 1$ if the statement inside is true and zero otherwise. The $\log$-likelihood can be maximized with respect to the model parameters $\Psi=\left(\beta_{I}^{\prime}, \sigma_{I}^{2}, \beta_{0}^{\prime} \sigma_{0}^{2}, \gamma^{\prime}\right)^{\prime}$ by a standard Newton-Raphson algorithm, so as to obtain the maximum likelihood estimator $\widehat{\Psi}$. Heteroskedasticity consistent standard errors are computed following White (1982). From a statistical point of view, it is worth underscoring that the use of a standard multiple linear regression to model the width of the price range is not advisable, in this case, for two reasons. First, the probability mass in $\$ 2$ introduces some nonlinearities in the parameters which, if ignored, lead to the inconsistency of the OLS estimator. Second, with respect to the Mixture Model, linear regression is less flexible in that it does not allow for the identification of factors affecting differently the extensive and intensive margin of the IPO price range.

\subsubsection{Network Measures}

The underwriters-investors network is built using connections that underwriters establish with each other when they are involved in the same equity underwriting syndicates as in Chuluun (2015) and Bajo et al. (2016). Following Cooney, Madureira, Singh, and Yang (2015), Chuluun (2015) and Rumokoy et al. (2017), we performed manual corrections when working with underwriter data because multiple variations of the same underwriter names appeared in the reported names; this consisted of checking all the names and manually correcting them when abbreviations and variations in punctuation or spelling implied the same agent. To investigate the impact of bank-fund relationships on the excess IPO range, we first built institutional investor-underwriter network measures. In our network, two agents are considered connected if they are or were active members of the same IPO at the same time. The purpose is to observe past interactions between regular investors and underwriters who participated in the same IPO (Rumokoy et al., 2017). The intuition is that the higher the number of connections an underwriter has (with other institutional investors) and the more centrally located it is within the network, the greater the ability to produce price relevant information. Following Hochberg, Ljungqvist, and Lu (2010), Chuluun (2015) and Bajo et al. (2016), we calculate a series of network centrality measures based on the institutional investor-underwriter connections formed in the three years prior to the IPO. Such measures are designed to indicate how each lead manager is positioned in the network, and how much information flows through each agent.

Following Hochberg, Ljungqvist, and Lu (2007), Larcker, So, and Wang (2013) and Houston, Lee, and Suntheim (2018) we first construct an nXn adjacency matrix whose (i, j)-element is a dummy which takes a value of one if agent- $\mathrm{i}$ and agent- $\mathrm{j}$ are socially connected and $\mathrm{N}$ denotes the total number of agents in the network: in our analysis $\mathrm{i}$ are banks and $\mathrm{j}$ are regular investors. In this case, we weight the adjacency matrix by the number of collaborations that occurred in the three years prior to the IPO. We then calculated centrality measures, including degree, eigenvector, and betweenness (Xiaohan \& Liu, 2016). The network measures are computed using directed binary data. More specifically, we construct the following four measures of network centrality:

- Degree is a way of measuring node activity by counting the total number of connections that an agent has in the network. It represents the sum of the row (or column) of the adjacency matrix. Because it is a function of the size of the network, we normalize degree by the maximum possible number of connections $\mathrm{N}-1$.

$$
\text { Degree }_{i}=\frac{\sum_{j} x_{i j}}{N-1}
$$

where $\mathrm{x}_{\mathrm{ij}}$ equals to one when there is a tie between underwriters $\mathrm{i}$ and investor $\mathrm{j}$, and $\mathrm{N}$ equals to the number of agents in the network.

- Eigenvector centrality is a way of measuring the total effects centrality of a node position by capturing how close an underwriter is to all other dealers. In other terms, agents having a higher eigenvector tend to connect to others who are well connected to the center of the network:

$$
e_{i}=\lambda \sum_{j} x_{i j} e_{j}
$$

where lambda is a constant represented by the biggest eigenvalue of the adjacency matrix and e is the eigenvector centrality score. We normalize eigenvector by dividing it by the maximum possible eigenvector element value for an $\mathrm{N}$ agent network.

- Betweenness measures the node control by capturing the capacity each underwriter has to act as an intermediary and to control valuable resources. Higher betweenness can lead to more access to information and a more advantageous position for controlling resources.

$$
\text { Betweenness } s_{\mathrm{i}}=\sum_{j k} b_{i j k}
$$


where bijk is the proportion of all paths linking distinct investor $\mathrm{j}$ and $\mathrm{k}$ that pass-through underwriter $\mathrm{i}$, and we normalize it by the maximum possible betweenness in the network.

\subsection{Variables}

Table 1, below, presents the definitions and sources of the dependent and independent variables used in this analysis. The definitions are those used in the Mixture Model. The dependent variable is the width of the range (high filing price-low filing price). The independent variables are classified in Panels A and B. Panel A presents the network centrality measures (discussed in Section 3.2) used to describe the position of the lead underwriter in both the underwriter networks and in the investor-underwriter networks. Panel B presents IPO characteristics and includes proxy variables relating to issuing firm attributes, deal (offer) characteristics, third-party certification, hot/cold market indicator, and a proxy for retail investor attention. In Panel B we make use of the underwriter reputation (UWR) variable because it is expected to increase the probability of being in the safe harbour range: according to Carter and Manaster (1990), low risk firms might select a prestigious underwriter to back up their low risk status.

Table 1. Variables: descriptions and sources

\begin{tabular}{|c|c|c|}
\hline Variable & Source & Description of variable \\
\hline \multicolumn{3}{|c|}{ Dependent variable } \\
\hline Width & Thomson & High filing price-low filing price of the filing range \\
\hline \multicolumn{3}{|c|}{ Panel A: Centrality measures } \\
\hline BIWdeg & Thomson & Degree of the directed and weighted network of underwriters-institutional investors \\
\hline BIWevc & Thomson & Eigenvector centrality of the directed and weighted network of underwriters-institutional investors \\
\hline BIWbtw & Thomson & Betweenness of the directed and weighted network of underwriters-institutional investors \\
\hline \multicolumn{3}{|c|}{ Panel B: IPO characteristics } \\
\hline UWR & $\begin{array}{l}\text { Jay Ritter } \\
\text { website }\end{array}$ & Underwriter's reputation ranking \\
\hline LEV & Compustat & Long-term debt scaled by total assets in the accounting period prior to the IPO \\
\hline EQ_RET & Thomson & $\begin{array}{l}\text { Logarithm }\left(1+\frac{\text { Secondary shares retained }}{\text { Shares offered }}\right) \text { where Secondary shares retained= Shares Outstanding }- \text { Total } \\
\text { shares sold }\end{array}$ \\
\hline AGE & $\begin{array}{l}\text { Jay Ritter } \\
\text { Web site }\end{array}$ & $\begin{array}{l}\text { Logarithm }(1+\text { firm age }) \text { where firm age is the number of years between the date the company was } \\
\text { founded and the IPO date }\end{array}$ \\
\hline SIZE & Compustat & Logarithm of total assets in the accounting period prior to the IPO \\
\hline SCARCITY & Thomson & Offer size divided by the initial filing size of the offer \\
\hline HOT_COLD & $\begin{array}{l}\text { Jay Ritter } \\
\text { website }\end{array}$ & $\begin{array}{l}\text { Average underpricing on net number of IPOs (excludes penny stocks, units, closed-end funds, etc.) } \\
\text { in the month before the issue date }\end{array}$ \\
\hline INV_ATT & $\begin{array}{l}\text { Google } \\
\text { Trends }\end{array}$ & $\begin{array}{l}\text { Logarithm of search frequency in Google (Search Volume Index (SVI)) in the month prior to the } \\
\text { IPO }\end{array}$ \\
\hline MIDP & Thomson & Midpoint of the initial price range \\
\hline TECH & Compustat & $\begin{array}{l}\text { Dummy variable equal to one if SIC code equal the ones identified in Kile and } \\
\text { Phillips (2009) }\end{array}$ \\
\hline
\end{tabular}

Note. This table presents the definitions of variables used in the Mixture Model. Panel A presents the centrality measures used to describe the position of the lead underwriter in the underwriter networks and in the investor-underwriter networks. Panel B includes proxy variables relating to issuing firm attributes, deal (offer) characteristics, third-party certification, hot/cold market indicator, and a proxy for retail investor attention. Data sources include Thomson One Deal, Compustat, Google Trends and the Jay Ritter website [http://bear.warrington.ufl.edu/ritter/ipodata.htm].

In addition, we include the proportion of stocks owned by insiders (EQ_ RET) because of the signalling effect it might have on the uncertainty surrounding the IPO (Brealey, Leland, \& Pyle, 1977; Downes \& Heinkel, 1982; Ritter, 1984; Feltham, Hughes, \& Simunic, 1991; Bradley \& Jordan, 2002; Loughran \& Ritter, 2004; Lowry \& Murphy, 2007). Moreover, the greater the retention, the lower the probability of required aftermarket price support. We also include a set of variables (AGE, SIZE, LEV and TECH) to account for the firm's intrinsic value, riskiness, and growth potentialities. The AGE (logarithm 1 plus) and asset logarithms (SIZE) are used here as a proxy for riskiness of the issuer (Beatty \& Ritter, 1986; Ritter, 1987). Prior studies suggest that younger and smaller companies are perceived as riskier (Field \& Karpoff, 2002; Loughran \& Ritter, 2004; Crain, Parrino, \& Srinivasan, 2017). Moreover, we compute the leverage (LEV) as the logarithm of long-term debt scaled by total assets in the accounting period prior to the IPO (Habib \& Ljungqvist, 2001) to control for ex ante uncertainty. A dummy variable (TECH) is included to evaluate industry focus. It takes the value of unity if the IPO firm is 
classified as high-tech, following the high technology SIC codes identified in Kile, and Phillips (2009), and zero otherwise. SCARCITY attempts to measure pre-issue demand for the IPO and is calculated as the final offer size divided by the first filed offer size, as in Goldstein, Irvine, and Puckett (2011). We control for market conditions with a hot and cold market indicator (HOT_COLD) that represents the average first-day return on the net number of IPOs that occurred in the month prior to the issue date (excluding penny stocks, units, closed-end funds, etc.). We compute the average level of underpricing of IPOs rather than inserting a dummy for hot and cold years because we assume that hot markets are characterized by a higher underpricing (Ibbotson \& Jaffe, 1975; Ritter, 1984; Helwege \& Liang, 2004; Ljungqvist, Nanda, \& Singh, 2006).

We also account for the possibility that in this restricted informational environment, retail investors' attention (proxied by Google Search Volume Index -SVI) might contain valuable clues about latent retail investor demand for the IPO (Colaco, Cesari, \& Hedge, 2017). This would help firms and underwriters to get more appropriate valuations for newly public firms, thus reducing the need for underwriters to engage in costly price stabilisation activities when trading begins (Chowdhry \& Nanda, 1996). The company's name and/or the ticker symbol, in the 30 days prior to the IPO, drove our term search in Google Trends and is used as a proxy for retail investor attention (INV_ATT) (Note 8) (Da, Enggelberg, \& Gao, 2011 and Colaco et al., 2017).

We control for the midpoint of the price range (MIDP) because, historically, the SEC has allowed an adjustment to the safe harbour parameters depending on the level of IPO prices. More specifically, the price range could not exceed a $\$ 2$ spread when the top of the range was $\$ 20$ or less, but a wider range was allowed for IPOs with a top of the range above $\$ 20$.

\section{Empirical Results}

\subsection{Descriptive Statistical Analysis}

Table 2. Summary statistics

\begin{tabular}{|c|c|c|c|c|c|}
\hline & $(1)$ & $(2)$ & (3) & (4) & (5) \\
\hline & mean & median & sd & $\min$ & $\max$ \\
\hline \multicolumn{6}{|c|}{ Dependent variables } \\
\hline Width & 1.762 & 2 & 0.806 & 0 & 10 \\
\hline \multicolumn{6}{|c|}{ Panel A: Centrality measures } \\
\hline BIWevc (\%) & 0.734 & 0.457 & 0.775 & 0 & 2.863 \\
\hline BIWdeg & 1.055 & 0.962 & 0.835 & 0.001 & 3.703 \\
\hline BIWbet (\%) & 0.111 & 0.094 & 0.090 & 0 & 0.536 \\
\hline \multicolumn{6}{|c|}{ Panel B: IPO characteristics and control variables } \\
\hline AGE (year) & 16.13 & 8 & 23.13 & 0 & 158 \\
\hline SIZE & 4.685 & 86.18 & 2.078 & -6.097 & 12.516 \\
\hline LEV & 0.267 & 0.093 & 0.437 & 0 & 8.448 \\
\hline EQ_RET & 0.604 & 0.652 & 1.165 & -12.43 & 4.220 \\
\hline UWR & 8.250 & 8.501 & 1.147 & 2.001 & 9.001 \\
\hline SCARCITY & 1.26 & 1 & 9.50 & 0.366 & 359.99 \\
\hline HOT_COLD & 21.22 & 14.9 & 21.19 & -7.4 & 115.3 \\
\hline INV_ATT & 33.75 & 30 & 26.82 & 0 & 100 \\
\hline TECH & 0.505 & 1 & 0.50 & 0 & 1 \\
\hline MIDP & 14.36 & 14 & 4.55 & 0 & 32.5 \\
\hline
\end{tabular}

Note. All accounting data are measured in the year prior to the offer. Width is the distance of low filing price from the high filing price of the filing range. The firm AGE is the natural logarithm of one plus the number of years from IPO firm founding year to the IPO issue year. SIZE is logarithm of the book value of assets in the accounting period before IPO. Leverage (LEV) is the logarithm of long-term debt scaled by total assets in the accounting period before the IPO. Equity retain (EQ_RET) is the logarithm of (1+ (Secondary shares retained / Shares offered)). Underwriter reputation (UWR) is based on rankings used in Carter and Manaster (1990) and updated on the Jay Ritter's web page. SCARCITY is calculated as the final offer size divided by the first filed offer size as in Goldstein et al. (2011). We also include: the hot and cold markets indicator (HOT_COLD) that represents the average first-day return on the net number of IPOs that occurred in the month prior to the issue date (excluding penny stocks, units, closed-end funds, etc.); the retail investor attention is proxied as the logarithm of search frequency in Google (Search Volume Index (SVI)) in the month prior to the IPO and the midpoint of the initial filing range. The dummy variable (TECH) equals one if the IPO firm is classified as high-tech, following the high-technology SIC codes identified in Kile and Phillips (2009), and equals zero, otherwise. MIDP is the midpoint of the initial filing range. Betweenness centrality is the number of shortest paths between all bank pairs that a bank lies on. Eigenvector centrality gives large values to those banks that have either many links, important links, or both many and important ones. Degree centrality denotes the number of first-degree links that a bank has in the network. All measures are calculated based on the participation in the same IPO in the previous three years. 
Table 2 presents the summary statistics for the 1,246 IPOs belonging to our sample. It shows that, on average, the sample firms go public 16 years after their foundation. The leverage, which is measured by the long-term debt scaled by the book value of assets, shows a $26 \%$ mean value. In addition, underwriters' average ranking is 8.2 ; given that the maximum value of the ranking range is 9 , we can conclude that only highly ranked underwriters followed issues in our sample. The shares owned by insiders are approximatively $60 \%$, which could be a positive signal of how confident the insiders are about the firm's prospects. The market conditions, captured by the net number of IPOs in the 30 days prior to the offering, show a normal situation of new issues market activity. Concerning the measure of investor attention, in our sample the IPO, the company name and/or the ticker symbol was searched 33.75 times on Google Trends, compared to a maximum of 100 times in the previous month. Of the companies in our sample, 50\% belong to the high-tech sector. The mean value of the midpoint of the range is 14.36. As in Xiaohan and Liu (2016) our centrality measures vary widely across the whole network and the maximum value is much different from the minimum. The descriptive statistics of the centrality measure for the underwriter-institutional investor network suggest that on average, the lead IPO underwriters in our sample had an eigenvector centrality equal to $73.4 \%$, a mean degree centrality over all periods equal to 1 , and a betweenness of $11.1 \%$.

Table 3, below, shows correlations across different network centrality measures and explanatory variables. Degree and eigenvector centrality appear to be positively and significantly correlated. This implies that lead managers who have a larger number of connections (higher degree) with other investors are associated with peers who themselves are well-connected (eigenvector) (Rumokoy et al., 2017). Correlations between other measures suggest a moderate linear relationship between the variables. Overall, the correlation coefficients suggest that network measures capture different aspects of the network.

Table 3. Correlations across different centrality measures and explanatory variables for sample period 2004-2016

\begin{tabular}{|c|c|c|c|c|c|c|c|c|c|c|c|c|}
\hline & BIWevc & BIWdeg & BIWbet & UWR & EQ_RET & HOT_COLD & SIZE & INV_ATT & LEV & SCARCITY & AGE & TECH \\
\hline BIWdeg & 0.740 & & & & & & & & & & & \\
\hline BIWbet & 0.584 & 0.621 & & & & & & & & & & \\
\hline UWR & 0.417 & 0.472 & 0.409 & & & & & & & & & \\
\hline EQ_RET & 0.043 & 0.026 & -0.006 & -0.021 & & & & & & & & \\
\hline HOT_COLD & 0.067 & -0.009 & 0.019 & -0.018 & 0.035 & & & & & & & \\
\hline SIZE & -0.006 & -0.021 & -0.058 & -0.044 & 0.078 & -0.17 & & & & & & \\
\hline INV_ATT & 0.069 & -0.003 & 0.117 & -0.002 & 0.028 & 0.022 & 0.216 & & & & & \\
\hline LEV & 0.015 & -0.005 & -0.036 & -0.051 & 0.057 & -0.151 & 0.201 & 0.136 & & & & \\
\hline SCARCITY & -0.057 & -0.031 & 0.024 & -0.026 & -0.056 & -0.203 & -.066 & 0.053 & 0.031 & & & \\
\hline AGE & 0.031 & 0.035 & -0.001 & 0.003 & 0.145 & 0.027 & 0.256 & 0.065 & 0.095 & -0.055 & & \\
\hline TECH & 0.018 & 0.025 & 0.088 & -0.004 & 0.095 & 0.205 & -.519 & -0.131 & -0.259 & 0.003 & -0.054 & \\
\hline MIDP & 0.003 & 0.040 & 0.008 & -0.018 & 0.168 & -0.022 & 0.588 & 0.197 & 0.076 & 0.064 & 0.110 & -0.379 \\
\hline
\end{tabular}

In Figure 1, below, we present the number of IPOs that set the offer price range lower than, equal to, or greater than $\$ 2$ across our sample period. As can be observed for each year, the majority of IPOs showed a price range equal to 2 dollars. This suggests that most of the firms in our sample are compliant with SEC guidelines.

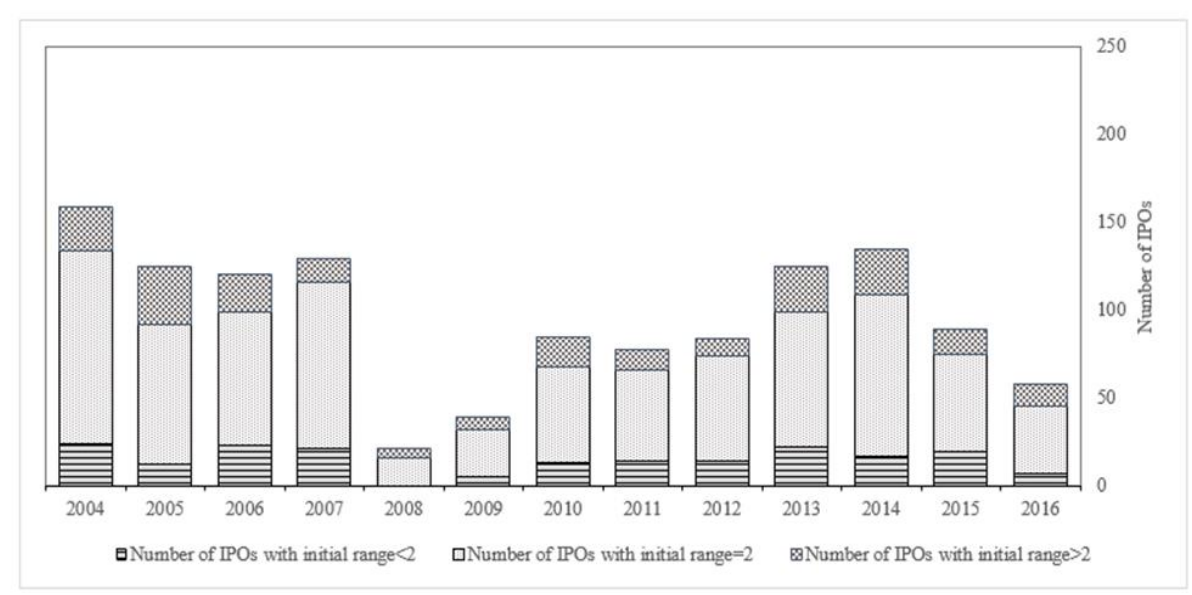

Figure 1. Initial price ranges of the sample firms for 2004-2016 


\subsection{Findings}

Table 4, below, provides the estimated coefficients of the Mixture Model. Panel A reports the results for the probability of being outside the safe harbour, which depends on the degree network measure and the other control variables, as described in Section 3.3. The estimated coefficient of the Mixture Model using other centrality network measures are presented in Appendix A, Table A1 and A2 (Note 9). The estimation results confirm H(1) IPOs characterized by a lead underwriter that is more centrally located in the network of institutional investors have a lower probability of setting a price range that is not compliant with the SEC's recommendations.

Our findings show that IPOs underwritten by book managers with more central investor networks are characterized by a higher probability of setting their price range within the safe harbour, thus confirming our first hypothesis.

We argue that the flexibility allowed by this rule is even more desirable when a network of pre-existing relationships with institutional investors is in place. By being able to avoid resorting to a formalized amendment, underwriters falling into the safe harbour preserve their reputation for fair dealing with issuers by discreetly adapting the IPO conditions to the demand and dumping cold IPO shares into their network funds. As recently argued by Degeorge and Pratobevera (2020), underwriters trying to dump cold shares on an affiliated fund are more likely to do so in aftermarket trading than during an initial IPO allocation; they would not want to run the risk of violating rule 10(f)-3, which protects fund shareholders by preventing an affiliated underwriter from placing or dumping unmarketable securities in the fund. This definitely provides a further explanation for why the unobtrusive flexibility for IPO conditions granted in safe harbour-compliant IPOs is largely appreciated by underwriters with more central fund networks. A central role of the underwriter in the network makes the safe harbour even more exploitable, as the adjusted IPO conditions can be more easily applied by means of quid pro quo or dumping ground agreements with regular funds.

Moreover, building on the recent findings of Colaco et al. (2017) and Da et al. (2011) on the relevance of retail investor attention to get more appropriate valuations, we also explore the impact of retail investor attention on the IPO price range setting, which is a proxy for the retail investor demand. Retail investor attention has a negative significant coefficient in all models, thus providing evidence that a higher interest from retail investors decreases the probability of pricing outside the safe harbour. This finding suggests that a bank prefers to be cautious when there is a high demand from retail investors considering that, also in this case, the realization of the demand will only occur later (when negotiations start).

Table 4. Mixture model of degree centrality measure

\begin{tabular}{|c|c|c|c|c|c|c|}
\hline & $\begin{array}{l}\text { Panel A: Pr } \\
\text { (width > 2) }\end{array}$ & & $\begin{array}{l}\text { Panel B: Mixture Model: density of } \\
\text { width }<=2\end{array}$ & & $\begin{array}{l}\text { Panel C: Mixture Model: density of } \\
\text { width > } 2\end{array}$ & \\
\hline const & $\begin{array}{l}-3.267 \\
(3.747)\end{array}$ & & $\begin{array}{l}-1.359 \\
(0.395)\end{array}$ & $* * *$ & $\begin{array}{c}2.937 \\
(0.593)\end{array}$ & $* * *$ \\
\hline UWR & $\begin{array}{c}0.065 \\
(0.227)\end{array}$ & & $\begin{array}{l}-0.041 \\
(0.027)\end{array}$ & & $\begin{array}{l}-0.048 \\
(0.026)\end{array}$ & $*$ \\
\hline EQ_RET & $\begin{array}{c}0.063 \\
(0.436)\end{array}$ & & $\begin{array}{c}0.017 \\
(0.040)\end{array}$ & & $\begin{array}{l}-0.139 \\
(0.075)\end{array}$ & $*$ \\
\hline HOT_COLD & $\begin{array}{l}-0.007 \\
(0.017)\end{array}$ & & $\begin{array}{c}0.001 \\
(0.001)\end{array}$ & & $\begin{array}{l}-0.002 \\
(0.003)\end{array}$ & \\
\hline SIZE & $\begin{array}{c}0.280 \\
(0.230)\end{array}$ & & $\begin{array}{l}-0.050 \\
(0.025)\end{array}$ & $* *$ & $\begin{array}{c}0.001 \\
(0.040)\end{array}$ & \\
\hline INV_ATT & $\begin{array}{l}-1.315 \\
(0.365)\end{array}$ & $* * *$ & $\begin{array}{c}0.025 \\
(0.034)\end{array}$ & & $\begin{array}{l}-0.133 \\
(0.062)\end{array}$ & $* *$ \\
\hline LEV & $\begin{array}{c}0.166 \\
(0.238)\end{array}$ & & $\begin{array}{l}-0.016 \\
(0.020)\end{array}$ & & $\begin{array}{l}-0.012 \\
(0.037)\end{array}$ & \\
\hline SCARCITY & $\begin{array}{l}-0.885 \\
(2.994)\end{array}$ & & $\begin{array}{c}0.345 \\
(0.322)\end{array}$ & & $\begin{array}{l}-0.650 \\
(0.348)\end{array}$ & $*$ \\
\hline AGE & $\begin{array}{c}0.078 \\
(0.240)\end{array}$ & & $\begin{array}{c}0.098 \\
(0.033)\end{array}$ & $* * *$ & $\begin{array}{l}-0.039 \\
(0.037)\end{array}$ & \\
\hline TECH & $\begin{array}{l}-1.377 \\
(1.344)\end{array}$ & & $\begin{array}{c}0.146 \\
(0.072)\end{array}$ & $* *$ & $\begin{array}{l}-0.134 \\
(0.091)\end{array}$ & \\
\hline
\end{tabular}




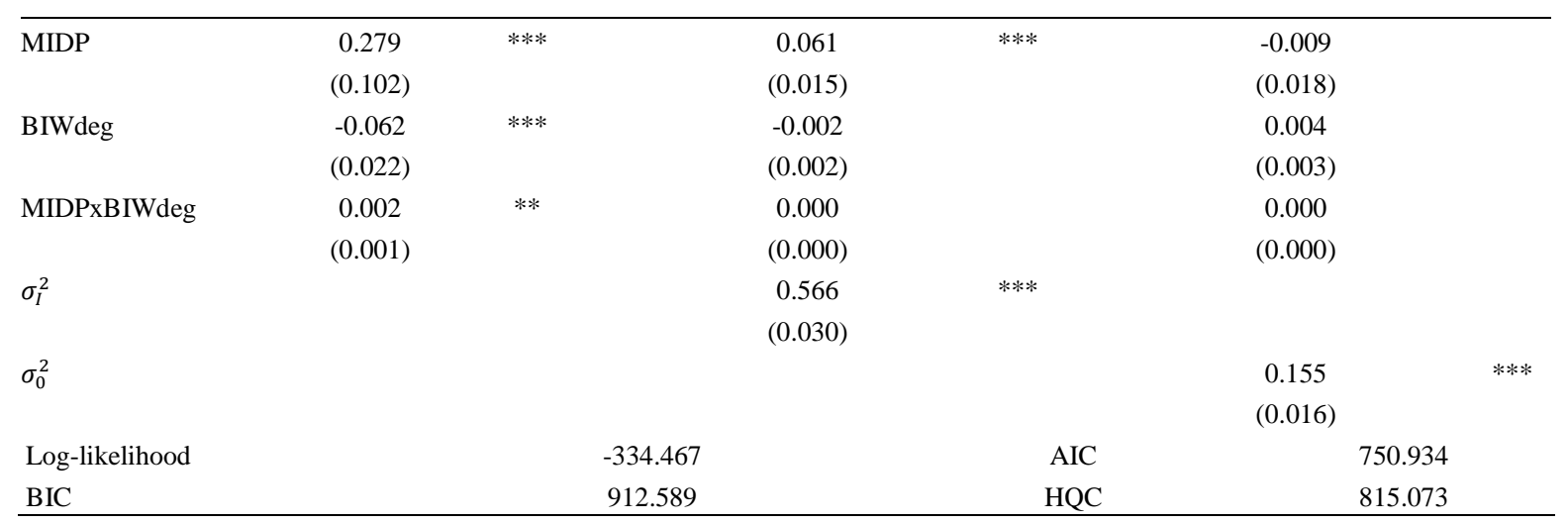

Note. The table presents the estimated coefficient of the Mixture Model using the degree centrality measures. In Panel A the probability of been outside the safe harbour is individually regressed over the degree centrality measure with a series of control variables as described in Section 3.3. Panel B and C provide results for the density of width in the case of a price range lower (or equal to) and greater than 2 , respectively. $*, * *$, and $* * *$ denote significance at the $10 \%, 5 \%$, and $1 \%$ levels, respectively. Standard errors are reported in parentheses.

As far as control variables are concerned, the midpoint of the range (MIDP) is the only significant variable in the IPO characteristics panel. We find a positive relationship between the midpoint of the range and the probability of being outside the safe harbour. Such empirical evidence is not totally unexpected, given that, historically, the SEC view was that the price range could not exceed a $\$ 2$ spread when the top of the range was $\$ 20$ or less, but a wider range was allowed for IPOs with a top of the range above \$20. Accordingly, IPOs with higher maximum in their range and consequently, a higher midpoint, can benefit from the less stringent two-dollar limit. The interaction terms with the centrality measures are also significant. This means that the need to ensure greater flexibility, because of the existence of a network of investors, is less evident in the case of IPOs with higher prices (and therefore higher midpoints). We argue that, if the offer price is low, the demand may be particularly volatile because bidders might be motivated by a long-term expected increase in value but might also have more short -term speculative goals that are favoured by the lower cost of the shares. In both cases, banks are likely to prefer more flexibility. In order to investigate the heterogeneous behaviour of centrality measures according to the midpoint value, we plot their partial effect on the probability of the width being greater than $\$ 2$ with respect to the midpoint level (Figures 2-4).

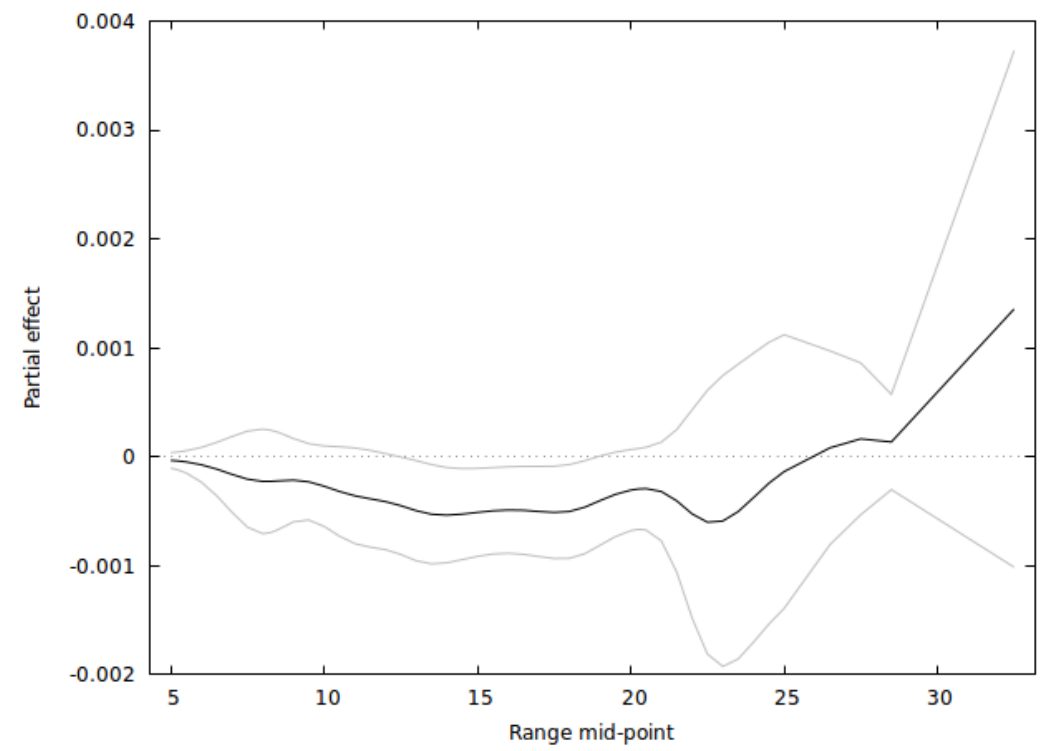

Figure 2. Partial effect of the degree centrality measure with respect to the midpoint of the range.

Note. The figure plots the partial effect (black curve) of the degree centrality measure with respect to the midpoint of the range. Confidence intervals at the $90 \%$ level are reported (grey curves). The curve is smoothed via non-parametric regression (Nadraya 1964; Watson, 1964), based on a Gaussian kernel with bandwidth equal to 1 . 


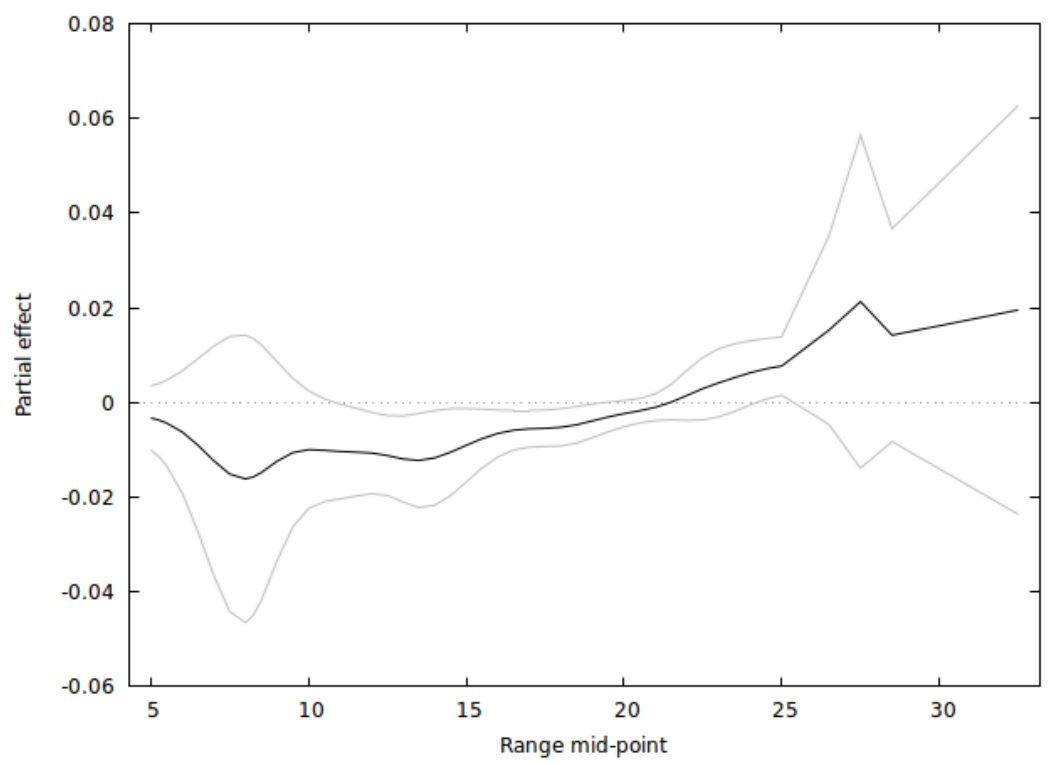

Figure 3. Partial effect of the betweenness centrality measure with respect to the midpoint of the range

Note. The figure plots the partial effect (black curve) of the betweenness centrality measure with respect to the midpoint of the range. Confidence intervals at the $90 \%$ level are reported (grey curves). The curve is smoothed via non-parametric regression (Nadraya 1964; Watson, 1964), based on a Gaussian kernel with bandwidth equal to 1.

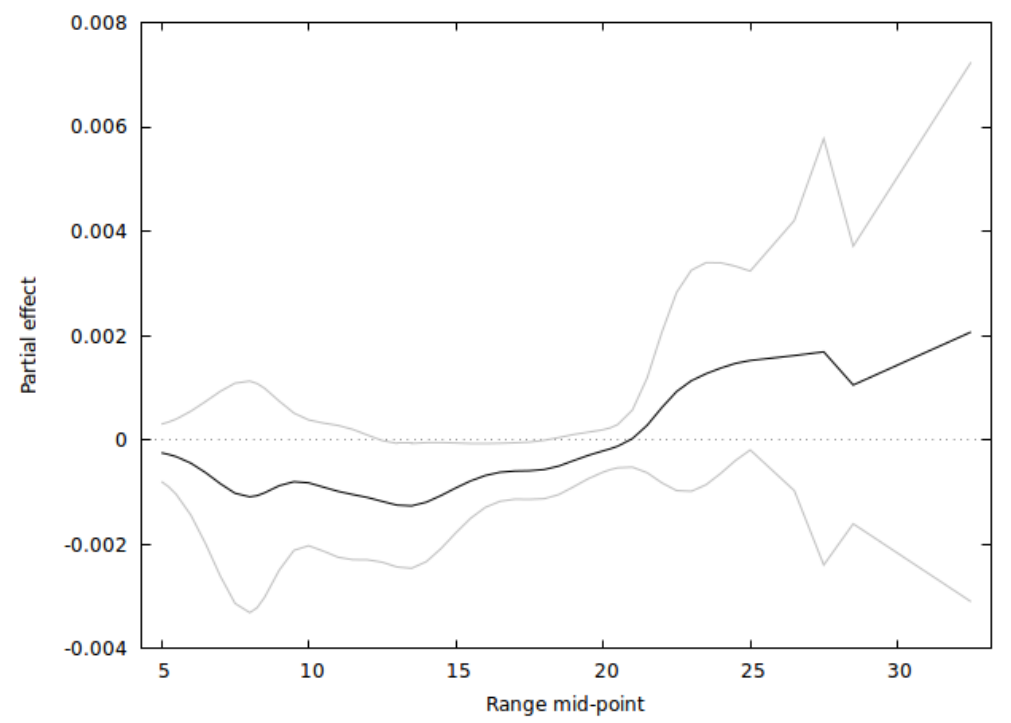

Figure 4. Partial effect of the eigenvector centrality measure with respect to the midpoint of the range

Note. The figure plots the partial effect (black curve) of the eigenvector centrality measure with respect to the midpoint of the range. Confidence intervals at the $90 \%$ level are reported (grey curves). The curve is smoothed via non-parametric regression (Nadraya 1964; Watson, 1964), based on a Gaussian kernel with bandwidth equal to 1.

The partial effects are smoothed using a non-parametric kernel regression (Nadaraya, 1964; Watson, 1964). The plots show that the effect of the centrality measures increases with the midpoint level. Moreover, the partial effects for the degree and betweenness measures become statistically significant at the $90 \%$ level for values of midpoint roughly between 12 and 20, confirming that the network effect depends on the price levels. However, a different result emerges looking at the eigenvector centrality measure, whose effect is statistically significant only for midpoint values between about 15 and 18. Panels B and C of Table 4 report the estimation result for the width, treated as a continuous variable, in the case of a price range lower than (or equal to) and greater than $\$ 2$, respectively. Disproving $\mathrm{H}(2)$ none of the network variables are associated with statistically significant 
coefficients. This suggests that, although repeated interactions between underwriters and their regular funds might increase information sharing in the early primary market, the effect of mitigating uncertainty surrounding the firm's value is not reflected in a smaller filing price range. From our observations thus far, centrality measures do exert an effect on the probability of the price range being set outside the SEC-imposed \$2 limit. However, it appears they do not contribute to an explanation for the width of the range, which seems to be more affected by the characteristics of the listing firm.

In this regard, although several studies have used the range as a proxy for the level of predictability of the IPO or the value of the issuing firm, in the present study we provide the first empirical evidence that the width is a signal of the firms' uncertainty. More specifically, we find that once the price range is set within the SEC guidelines (Panel B), companies with a higher level of certainty (larger in terms of SIZE and belonging to non-high-tech or innovative sectors) are those experiencing narrower ranges. On the contrary, more mature companies (Note 10) (AGE), or high-priced firms (MIDP) are perceived as riskier, resulting in a broader IPO filing range.

In addition, we provide evidence that, when the price range is greater that $\$ 2$ (Panel $\mathrm{C}$ ), the underwriter reputation (UWR) contributes to a reduction of the price range and so do the variables referring to demand for shares (SCARCITY), proportion of stocks retained by insiders (EQ_RET), and attention of retail investors (INV_ATT). As in Colaco et al. (2017), we find that an increase in retail investors' attention is positively related to more precise initial valuations, thus suggesting that it can be used as a forerunner variable for retail demand in the aftermarket (Barber \& Odean, 2008).

\section{Conclusion}

In this paper, we study the impact of the heretofore unexplored underwriter-institutional investor networks on the IPO price range, by applying social network analysis (SNA) measures to a sample of 1,246 U.S. IPOs issued between 2004 and 2016. Keeping in mind the price range guidance (safe harbour) provided by the SEC, we estimated a Mixture Model that explores the role played by the network in the likelihood that the price range is set outside the SEC parameters, as well as in the density of width of the price range.

Our results reveal that IPOs underwritten by book managers with more central investor networks show a higher probability of setting their price range within the safe harbour. We argue that, despite some flexibility being commonly accepted in every new listing (making it possible to discreetly adapt the IPO conditions to the demand and to preserve the underwriter's reputation for fair dealing with issuers), when a network of pre-existing relationships with institutional investors is in place, this type of flexibility is even more highly appreciated. If IPO conditions can be adjusted according to the information coming from the bookbuilding, network funds might enable underwriters to dump shares on funds in the event of cold IPOs and to be favoured with a quid pro quo in the case of hot issues.

We also find that when the width of the range is under analysis, firms' characteristics, more than investors' networks, carry more weight in terms of their effect on the range. Such a result suggests that, although information production and/or revelation might already take place in the due diligence phase through a network of pre-existing relationships with institutional investors, the information that informally circulates at this time does not produce any significant effect on the width of the price range. Nevertheless, we provide evidence that the price range width does serve as a proxy for the uncertainty of the listing firms, as argued by previous literature, especially in terms of its size, age, and sector.

The present paper adds to previous literature by providing new evidence on the mechanisms that determine how IPO price ranges are set in the due diligence step. Indeed, although several scholars have used the initial filing range as a proxy for uncertainty about the value of IPO shares, no study has provided empirical evidence of the relationship between the characteristics of the issuing firm and/or the IPO and the width of the range. Our analysis reveals that the width of the initial filing range is related to both the issuing firms' and IPOs' characteristics and is therefore able to signal the quality of the firms. Moreover, differently from previous studies, we investigate the extent to which networking patterns between underwriters and institutional investors might affect the way the price range is set, providing evidence that underwriters with more central networks are more likely to bring about price ranges that are set within the safe harbour and are therefore narrower in width. From a practical point of view, our evidence offers a further possible explanation for why issuers would hire underwriters that are located in a strong network of funds, despite the conflicts of interest that might arise from such relationships. Underwriters that are centrally positioned in their fund networks might point to a greater predictability of the final offer price thanks to reduced price volatility in the primary market, which in turns lessens the uncertainty that issuers face regarding the final conditions of the IPO. 


\section{References}

Bajo, E., Chemmanur, T. J., Simonyan, K., \& Tehranian, H. (2016). Underwriter networks, investor attention, and initial public offerings. Journal of Financial Economics, 122(2), 376-408. https://doi.org/10.1016/j.jfineco.2015.12.001

Beatty, R. P. \& Ritter, J. R. (1986). Investment banking, reputation, and the underpricing of initial public $\begin{array}{llll}\text { offerings. Journal of } & \text { Financial }\end{array}$ https://doi.org/10.1016/0304-405X(86)90055-3

Beatty, R., Riffe, S., \& Thompson, R. (2000). Ipo pricing with accounting information. Southern Methodist University Working Paper.

Bloomberg Corporate Law Journal December. (2007). Securities Offerings - Completing your IPO as Market Conditions Shift on Pricing Day.

Bradley, D. J., \& Jordan, B. D. (2002). Partial adjustment to public information and ipo underpricing. Journal of Financial and Quantitative Analysis, 37(04), 595-616. https://doi.org/10.2307/3595013

Brealey, R., Leland, H. E., \& Pyle, D. H. (1977). Informational asymmetries, financial structure, and financial intermediation. The Journal of Finance, 32(2), 371-387. https://doi.org/10.2307/2326770

Butler, A. W., \& Wan, H. (2005). Investment bank compensation and IPO pricing. Working Paper. https://doi.org/10.2139/ssrn.875422

Carter, R., \& Manaster, S. (1990). Initial public offerings and underwriter reputation. The Journal of Finance, 45(4), 1045-1067. https://doi.org/10.1111/j.1540-6261.1990.tb02426.x

Chowdhry, B., \& Nanda, V. (1996), Stabilization, Syndication, and Pricing of IPOs. Journal of Financial and Quantitative Analysis, 31(1), 25-42. https://doi.org/10.2307/2331385

Chuluun, T. (2015). The role of underwriter peer networks in IPOs. Journal of Banking \& Finance, 51, 62-78. https://doi.org/10.1016/j.jbankfin.2014.11.001

Colaco, H. M., De Cesari, A., \& Hegde, S. P. (2017). Retail investor attention and IPO valuation. European Financial Management, 23(4), 691-727. https://doi.org/10.1111/eufm.12113

Cooney, J. W., Madureira, L., Singh, A. K., \& Yang, K. (2015). Social ties and IPO outcomes. Journal of Corporate Finance, 33, 129-146. https://doi.org/10.1016/j.jcorpfin.2015.05.003

Corwin, S. A., \& Schultz, P. (2005). The role of IPO underwriting syndicates: Pricing, information production, and underwriter competition. The Journal of Finance, 60(1), 443-486. https://doi.org/10.1111/j.1540-6261.2005.00735.x

Crain, N., Parrino, R., \& Srinivasan, R. (2017). Uncertainty, Prospectus Content, and the Pricing of Initial Public Offerings. Working Paper. https://doi.org/10.2139/ssrn.3082429

Da, Z., Enggelberg, J., \& Gao, P. (2011). In search of attention. The Journal of Finance, 66(5), 1461-1499. https://doi.org/10.1111/j.1540-6261.2011.01679.x

Degeorge, F., \& Pratobevera, G. (2020). Nepotism in IPOs: Consequences for issuers and investors. Swiss Finance Institute Research Paper n. 20-68, 1-76. http://dx.doi.org/10.2139/ssrn.3677810

Deloof, M., De Maeseneire, W., \& Inghelbrecht, K. (2009). How do investment banks value initial public offerings (ipos)? Journal of Business Finance \& Accounting, 36(1-2), 130-160. https://doi.org/10.1111/j.1468-5957.2008.02117.x

Downes, D. H., \& Heinkel, R. (1982). Signaling and the valuation of unseasoned new issues. The Journal of Finance, 37(1), 1-10. https://doi.org/10.2307/2327113

Feltham, G. A., Hughes, J. S., \& Simunic, D. A. (1991). Empirical assessment of the impact of auditor quality on the valuation of new issues. Journal of accounting and Economics, 14(4), 375-399. https://doi.org/10.1016/0165-4101(91)90009-D

Field, L. C., \& Karpoff, J. M. (2002). Takeover defenses of ipo firms. The Journal of Finance, 57(5), 1857-1889. https://doi.org/10.1111/0022-1082.00482

Field, L. C., \& Lowry, M. (2009). Institutional versus individual investment in IPOs: The importance of firm fundamentals. Journal of Financial and Quantitative Analysis, 44(3), 489-516. https://doi.org/10.1017/S0022109009990032 
Goldstein, M. A., Irvine, P., \& Puckett, A. (2011). Purchasing ipos with commissions. Journal of Financial and Quantitative Analysis, 46(5), 1193-1225. https://doi.org/10.1017/S0022109011000317

Goyal, V., \& Tam, H. K. (2013). Investor characteristics, relationships, and IPO allocations. Working Paper.

Habib, M. A., \& Ljungqvist, A. P. (2001). Underpricing and entrepreneurial wealth losses in IPOs: Theory and evidence. The Review of Financial Studies, 14(2), 433-458. https://doi.org/10.1093/rfs/14.2.433

Hanley, K. W., \& Hoberg, G. (2010). The information content of IPO prospectuses. The Review of Financial Studies, 23(7), 2821-2864. https://doi.org/10.1093/rfs/hhq024

Hanley, K. W. (1993). The underpricing of initial public offerings and the partial adjustment phenomenon. Journal of Financial Economics, 34(2), 231-250. https://doi.org/10.1016/0304-405X(93)90019-8

Helwege, J., \& Liang, N. (2004). Initial public offerings in hot and cold markets. Journal of financial and Quantitative Analysis, 39(3), 541-569. https://doi.org/10.1017/S0022109000004026

Hochberg, Y. V., Ljungqvist, A., \& Lu, Y. (2007). Whom you know matters: Venture capital networks and investment performance. The Journal of Finance, 62(1), 251-301. https://doi.org/10.1111/j.1540-6261.2007.01207.x

Hochberg, Y. V., Ljungqvist, A., \& Lu, Y. (2010). Networking as a barrier to entry and the competitive supply of venture capital. The Journal of Finance, 65(3), 829-859. https://doi.org/10.1111/j.1540-6261.2010.01554.x

Houston, J. F., Lee, J., \& Suntheim, F. (2018). Social networks in the global banking sector. Journal of Accounting and Economics, 65(2-3), 237-269. https://doi.org/10.1016/j.jacceco.2017.11.006

Ibbotson, R. G., \& Jaffe, J. F. (1975). "Hot issue" markets. The Journal of Finance, 30(4), 1027-1042. https://doi.org/10.2307/2326721

Jenkinson, T., Jones, H., \& Suntheim, F. (2018). Quid pro quo? What factors influence IPO allocations to investors? The Journal of Finance, 73(5), 2303-2341. https://doi.org/10.1111/jofi.12703

Jenkinson, T., Morrison, A. D., \& Wilhelm, W. J. (2006). Why are European IPOs so Rarely Priced Outside the Indicative Price Range? Journal of Financial Economics, 80(1), 185-209. https://doi.org/10.1016/j.jfineco.2005.05.001

Kile, C. O., \& Mary, E. P. (2009). Using industry classification codes to sample high-technology firms: Analysis and recommendations. Journal of Accounting, Auditing \& Finance, 24(1), 35-58. https://doi.org/10.1177/0148558X0902400104

Kim, M., \& Ritter, J. R. (1999). Valuing IPOs. Journal of Financial Economics, 53(3), 409-437. https://doi.org/10.1016/S0304-405X(99)00027-6

Larcker, D. F., So, E. C., \& Wang, C. C. (2013). Boardroom centrality and firm performance. Journal of Accounting and Economics, 55(2-3), 225-250. https://doi.org/10.1016/j.jacceco.2013.01.006

Ljungqvist, A., Nanda, V., \& Singh, R. (2006). Hot markets, investor sentiment, and IPO pricing. The Journal of Business, 79(4), 1667-1702. https://doi.org/10.1086/503644

Loughran, T., \& Ritter, J. (2004). Why has IPO underpricing changed over time? Financial Management, 33(3), 5-37. https://doi.org/10.2307/3666262

Lowry, M., \& Murphy, K. J. (2007). Executive stock options and IPO underpricing. Journal of Financial Economics, 85(1), 39-65. https://doi.org/10.1016/j.jfineco.2006.05.006

Lowry, M., \& Schwert, G. (2004). Is the IPO pricing process efficient? Journal of Financial Economics, 71(1), 3-26. https://doi.org/10.1016/S0304-405X(03)00205-8

Lowry, M., Michaely, R., Volkova, E., et al. (2017). Initial public offerings: A synthesis of the literature and directions for future research. Foundations and Trends in Finance, 11(3-4), 154-320. https://doi.org/10.1561/0500000050

Myers, S. C. (1977). Determinants of corporate borrowing. Journal of Financial Economics, 5(2), 147-175. https://doi.org/10.1016/0304-405X(77)90015-0

Nadaraya, E. A. (1964). On estimating regression. Theory of Probability \& Its Applications, 9(1), 141-142. https://doi.org/10.1137/1109020

Reuter, J. (2006). Are IPO allocations for sale? evidence from mutual funds. The Journal of Finance, 61(5), 2289-2324. https://doi.org/10.1111/j.1540-6261.2006.01058.x 
Ritter, J. R., \& Welch, I. (2002). A review of IPO activity, pricing, and allocations. The Journal of Finance, 57(4), 1795-1828. https://doi.org/10.1111/1540-6261.00478

Ritter, J. R., \& Zhang, D. (2007). Affiliated mutual funds and the allocation of initial public offerings. Journal of Financial Economics, 86(2), 337-368. https://doi.org/10.1016/j.jfineco.2006.08.005

Ritter, J. R. (1984). The "hot issue" market of 1980. Journal of Business, 57(2), 215-240. https://doi.org/10.1086/296260

Ritter, J. R. (1987). The costs of going public. Journal of Financial Economics, 19(2), 269-281. https://doi.org/10.1016/0304-405X(87)90005-5

Roosenboom, P. (2012). Valuing and pricing ipos. Journal of Banking \& Finance, 36(6), 1653-1664. https://doi.org/10.1016/j.jbankfin.2012.01.009

Rumokoy, L. J., Neupane, S., Chung, R. Y., \& Vithanage, K. (2017). Underwriter network structure and political connections in the Chinese IPO market. Pacific-Basin Finance Journal, 54, 199-214. https://doi.org/10.1016/j.pacfin.2017.10.005

Watson, G. S. (1964). Smooth regression analysis. Sankhyāa: The Indian Journal of Statistics, Series A, 359-372. Retrieved https://www.scirp.org/(S(351jmbntvnsjt1aadkposzje))/reference/ReferencesPapers.aspx?ReferenceID=8376 56

White, H. (1982). Maximum likelihood estimation of misspecified models. Econometrica: Journal of the Econometric Society, 50(1), 1-25. https://doi.org/10.2307/1912526

Xiaohan, L., \& Yucan, L. (2016). Study on underwriting network and its role in ipo underpricing. In Service Systems and Service Management (ICSSSM), 2016 13th International Conference on, p. 16. IEEE. https://doi.org/10.1109/ICSSSM.2016.7538506

\section{Notes}

Note 1. Until September 2001 the SEC generally considered a price range of greater than $\$ 2$, or $10 \%$ of the lower price, as a bona fide estimate; this guideline was re-set in the volatile post-9/11 time period to a greater than $\$ 2$, or $20 \%$ of the lower price, price spread (Jenkinson et al., 2006). However, the SEC has also recommended that a bona fide estimate for the price range used in an IPO should be no more than $\$ 2$ or $20 \%$ of the high end of the range (Bloomberg Corporate Law Journal, 2007).

Note 2. For example, the need to obtain a new auditor's consent and updated signature pages as well as clear any comments from the SEC on the new disclosure.

Note 3. In many studies, the midpoint of the initial price range (i.e., average of high and low prices) is used as an unbiased estimator of final valuation (offer price) (Hanley, 1993; Bradley \& Jordan, 2002; Loughran \& Ritter, 2004). However, Lowry, and Schwert (2004) find that the midpoint is not an unbiased predictor of the final offer price since public information is not fully incorporated into the initial price range.

Note 4. One limitation to empirically examining underwriter-institutional investor networks is that investment banks are not required to disclose their order book and allocations' schedule.

Note 5. There has been little research on how issuers and underwriters determine the initial value of the IPO and how this estimate is reflected in the initial range. Theory suggests the use of discounted cash flow as the conceptual foundation of valuation (Myers, 1977). However, there are several methods available for stock valuation such as the dividend discount model (DDM) and the discounted free cash flow (DFCF) method, and valuation approaches that rely on multiples of firms in similar industries and firms involved in similar transactions (Deloof et al., 2009). Kim and Ritter (1999) examine the use of price-earnings and other multiples of comparable firms as benchmarks for valuing IPOs. They argue that accounting information and comparable firm multiples alone are not enough to ensure accurate pricing when determining the initial price range because IPO pricing is largely related to information about the market demand revealed during the bookbuilding. On the contrary, Beatty et al. (2000) suggest that underwriters do not use any additional accounting information in setting offer price not previously considered in setting the filing price range. Roosenboom (2012) shows that underwriters often use multiples valuation, dividend discount models, and discounted cash flow models to determine fair value and these three valuation techniques have similar bias, accuracy and explainability.

Note 6. Stocks with a price below $\$ 5.00$ per share are subject to the provisions of the Securities Enforcement 
Remedies and Penny Stock Reform Act of 1990, aimed at reducing fraud and abuse in the penny stock market (Ritter, 1991).

Note 7. Some information about issuing firm characteristics is also included into TOD. Because of the absence of some relevant financial items and for ease of comparison we prefer to use Compustat as the only source of financial statement information.

Note 8. As Da et al. (2011) point out, valid SVI values are not available for some stocks because individuals may not use the SDC company name to search for the stock using Google. In addition to this, Google Trends truncates the output and returns missing values for SVIs with insufficient searches (Colaco et al., 2017).

Note 9. For completeness in Appendix B Table B1, we also show the results of the OLS model for different centrality network measures.

Note 10. We interpret our finding in light of the fact that investors may perceive this delayed market access as a bad sign of the quality of the company, considering that the median age of firms going public is low (Loughran \& Ritter, 2001).

\section{Appendix A}

Table A1. Mixture model of betweenness centrality measure

\begin{tabular}{|c|c|c|c|}
\hline & Panel A: $\operatorname{Pr}$ (width > 2) & Panel B: Mixture Model: density of width $<=2$ & Panel C: Mixture Model: density of width $>2$ \\
\hline \multirow[t]{2}{*}{ const } & -0.604 & $-1.309 * * *$ & $2.891 * * *$ \\
\hline & $(3.653)$ & $(0.403)$ & $(0.657)$ \\
\hline \multirow[t]{2}{*}{ UWR } & -0.105 & $-0.053 * *$ & $-0.062 * *$ \\
\hline & $(0.224)$ & $(0.025)$ & $(0.029)$ \\
\hline \multirow[t]{2}{*}{ EQ_RET } & -0.121 & 0.019 & $-0.144^{*}$ \\
\hline & $(0.366)$ & $(0.040)$ & $(0.082)$ \\
\hline \multirow[t]{2}{*}{ HOT_COLD } & -0.008 & 0.001 & -0.001 \\
\hline & $(0.017)$ & $(0.001)$ & $(0.003)$ \\
\hline \multirow[t]{2}{*}{ SIZE } & $0.387^{*}$ & $-0.049^{*}$ & -0.023 \\
\hline & $(0.225)$ & $(0.025)$ & $(0.048)$ \\
\hline \multirow[t]{2}{*}{ INV_ATT } & $-1.114 * * *$ & 0.024 & $-0.207 * * *$ \\
\hline & $(0.339)$ & $(0.033)$ & $(0.071)$ \\
\hline \multirow[t]{2}{*}{ LEV } & 0.032 & -0.017 & 0.039 \\
\hline & $(0.225)$ & $(0.020)$ & $(0.040)$ \\
\hline \multirow[t]{2}{*}{ SCARCITY } & -1.010 & 0.339 & -0.545 \\
\hline & (3.010) & $(0.330)$ & $(0.395)$ \\
\hline \multirow[t]{2}{*}{ AGE } & 0.153 & $0.097 * * *$ & $-0.046^{*}$ \\
\hline & $(0.220)$ & $(0.033)$ & $(0.028)$ \\
\hline \multirow[t]{2}{*}{ TECH } & -1.482 & $0.131^{*}$ & $-0.213^{*}$ \\
\hline & $(0.940)$ & $(0.073)$ & $(0.114)$ \\
\hline \multirow[t]{2}{*}{ MIDP } & 0.122 & $0.063^{* * *}$ & 0.014 \\
\hline & $(0.086)$ & $(0.016)$ & $(0.017)$ \\
\hline \multirow[t]{2}{*}{ BIWbet } & $-1.258 * *$ & -0.011 & 0.069 \\
\hline & $(0.488)$ & $(0.021)$ & $(0.048)$ \\
\hline \multirow[t]{2}{*}{ MIDPxBIWbet } & $0.057 * *$ & 0.001 & -0.002 \\
\hline & $(0.022)$ & $(0.001)$ & $(0.002)$ \\
\hline \multirow[t]{2}{*}{$\sigma_{I}^{2}$} & & $0.566^{* * *}$ & \\
\hline & & $(0.031)$ & \\
\hline \multirow[t]{2}{*}{$\sigma_{0}^{2}$} & & & $0.163 * * *$ \\
\hline & & & $(0.024)$ \\
\hline Log-likelihood & & -336.076 & 754.153 \\
\hline $\mathrm{BIC}$ & & 915.915 & 818.327 \\
\hline
\end{tabular}

Note. Variable descriptions are provided in the Table 1. In Panel A the probability of being outside the safe harbour is individually regressed over the betweenness centrality measure with a series of control variables as described in Section 3.3. Panels B and C provide results for the density of width in the case of a price range lower than (or equal to) and greater than 2 , respectively. $*, * *$, and *** denote significance at the $10 \%, 5 \%$, and $1 \%$ levels, respectively. Standard errors are reported in parentheses. 
Table A2. Mixture model of eigenvector centrality measure

\begin{tabular}{|c|c|c|c|c|c|c|c|}
\hline \multirow[b]{2}{*}{ const } & \multicolumn{2}{|c|}{ Panel A: $\operatorname{Pr}$ (width > 2) } & \multicolumn{2}{|c|}{$\begin{array}{r}\text { Panel B: Mixture Model: } \\
\text { density of width }<=2\end{array}$} & & \multicolumn{2}{|c|}{$\begin{array}{r}\text { Panel C: Mixture Model: } \\
\text { density of width }>2 \\
\end{array}$} \\
\hline & -2.156 & & -1.342 & $* * *$ & & 2.930 & $* * *$ \\
\hline & $(3.230)$ & & $(0.380)$ & & & $(0.671)$ & \\
\hline \multirow[t]{2}{*}{ UWR } & -0.110 & & -0.038 & & & -0.047 & \\
\hline & $(0.199)$ & & $(0.025)$ & & & $(0.033)$ & \\
\hline \multirow[t]{2}{*}{ EQ_RET } & -0.017 & & 0.017 & & & -0.071 & \\
\hline & $(0.359)$ & & $(0.039)$ & & & $(0.084)$ & \\
\hline \multirow[t]{2}{*}{ HOT_COLD } & -0.002 & & 0.001 & & & 0.001 & \\
\hline & $(0.016)$ & & $(0.001)$ & & & $(0.003)$ & \\
\hline \multirow[t]{2}{*}{ SIZE } & 0.439 & $*$ & -0.051 & $* *$ & & -0.013 & \\
\hline & $(0.241)$ & & $(0.025)$ & & & $(0.051)$ & \\
\hline \multirow[t]{2}{*}{ INV_ATT } & -1.075 & $* * *$ & 0.026 & & & -0.202 & $* *$ \\
\hline & $(0.345)$ & & $(0.033)$ & & & $(0.081)$ & \\
\hline \multirow[t]{2}{*}{ LEV } & 0.043 & & -0.016 & & & 0.021 & \\
\hline & $(0.229)$ & & $(0.020)$ & & & $(0.042)$ & \\
\hline \multirow[t]{2}{*}{ SCARCITY } & -1.033 & & 0.339 & & & -0.556 & \\
\hline & $(2.863)$ & & $(0.318)$ & & & $(0.447)$ & \\
\hline \multirow[t]{2}{*}{ AGE } & 0.103 & & 0.097 & $* * *$ & & -0.063 & $*$ \\
\hline & $(0.212)$ & & $(0.033)$ & & & $(0.035)$ & \\
\hline \multirow[t]{2}{*}{ TECH } & -1.692 & $*$ & 0.144 & $* *$ & & -0.106 & \\
\hline & $(0.963)$ & & $(0.072)$ & & & $(0.104)$ & \\
\hline \multirow[t]{2}{*}{ MIDP } & 0.165 & $*$ & 0.059 & $* * *$ & & 0.001 & \\
\hline & $(0.085)$ & & $(0.014)$ & & & $(0.017)$ & \\
\hline \multirow[t]{2}{*}{ BIWevc } & -0.154 & $* *$ & -0.003 & & & 0.003 & \\
\hline & $(0.067)$ & & $(0.001)$ & & & $(0.005)$ & \\
\hline \multirow[t]{2}{*}{ MIDPxBIWevc } & 0.007 & $* *$ & 0.000 & & & 0.000 & \\
\hline & $(0.003)$ & & $(0.000)$ & & & $(0.000)$ & \\
\hline$\sigma_{I}^{2}$ & & & $\begin{array}{r}0.564 \\
(0.030)\end{array}$ & $* * *$ & & & \\
\hline \multirow[t]{4}{*}{$\sigma_{0}^{2}$} & & & & & & 0.178 & $* * *$ \\
\hline & & & & & & $(0.017)$ & \\
\hline & $\log$ & -likelihood & -337.577 & & AIC & 757.153 & \\
\hline & & BIC & 918.916 & & HQC & 821.328 & \\
\hline
\end{tabular}

Note. This table presents the estimated coefficient of the Mixture Model using the eigenvector centrality measures. Variable descriptions are provided in the Table1. In Panel A the probability of been outside the safe harbour is individually regressed over the eigenvector centrality measure with a series of control variables as described in Section 3.3. Panel B and C provide results for the density of width in the case of a price range lower than (or equal to) and greater than 2, respectively. *, **, and *** denote significance at the $10 \%, 5 \%$, and $1 \%$ levels, respectively. Standard errors are reported in parentheses. 


\section{Appendix B}

Table B1. OLS model of centrality measures

\begin{tabular}{|c|c|c|c|c|c|c|c|}
\hline \multirow[b]{2}{*}{ const } & \multicolumn{3}{|c|}{$(1)$} & \multicolumn{2}{|l|}{$(2)$} & \multicolumn{2}{|l|}{ (3) } \\
\hline & & 0.738 & & 0.657 & & 0.724 & $*$ \\
\hline & & $(0.449)$ & & $(0.433)$ & & $(0.426)$ & \\
\hline \multirow[t]{2}{*}{ UWR } & & -0.058 & $* *$ & -0.041 & & -0.044 & $*$ \\
\hline & & $(0.026)$ & & $(0.028)$ & & $(0.026)$ & \\
\hline \multirow[t]{2}{*}{ EQ_RET } & & 0.022 & & 0.022 & & 0.024 & \\
\hline & & $(0.041)$ & & $(0.041)$ & & $(0.041)$ & \\
\hline \multirow[t]{2}{*}{ HOT_COLD } & & 0.001 & & 0.001 & & 0.001 & \\
\hline & & $(0.001)$ & & $(0.001)$ & & $(0.001)$ & \\
\hline \multirow[t]{2}{*}{ SIZE } & & -0.045 & $*$ & -0.046 & $*$ & -0.045 & $*$ \\
\hline & & $(0.026)$ & & $(0.026)$ & & $(0.026)$ & \\
\hline \multirow[t]{2}{*}{ INV_ATT } & & -0.028 & & -0.029 & & -0.027 & \\
\hline & & $(0.040)$ & & $(0.041)$ & & $(0.040)$ & \\
\hline \multirow[t]{2}{*}{ LEV } & & -0.019 & & -0.018 & & -0.018 & \\
\hline & & $(0.022)$ & & $(0.022)$ & & $(0.022)$ & \\
\hline \multirow[t]{2}{*}{ SCARCITY } & & 0.360 & & 0.354 & & 0.352 & \\
\hline & & $(0.335)$ & & $(0.325)$ & & $(0.325)$ & \\
\hline \multirow[t]{2}{*}{ AGE } & & 0.082 & $* *$ & 0.083 & $* *$ & 0.083 & $* *$ \\
\hline & & $(0.036)$ & & $(0.036)$ & & $(0.036)$ & \\
\hline \multirow[t]{2}{*}{$\mathrm{TECH}$} & & 0.069 & & 0.075 & & 0.074 & \\
\hline & & $(0.079)$ & & $(0.079)$ & & $(0.079)$ & \\
\hline \multirow[t]{2}{*}{ MIDP } & & 0.082 & $* * *$ & 0.082 & $* * *$ & 0.077 & $* * *$ \\
\hline & & $(0.015)$ & & $(0.014)$ & & $(0.013)$ & \\
\hline \multirow[t]{2}{*}{ BIWbet } & & -0.004 & & & & & \\
\hline & & $(0.019)$ & & & & & \\
\hline \multirow[t]{2}{*}{ MIDPxBIWbet } & & 0.000 & & & & & \\
\hline & & $(0.001)$ & & & & & \\
\hline \multirow[t]{2}{*}{ BIWdeg } & & & & -0.001 & & & \\
\hline & & & & $(0.002)$ & & & \\
\hline \multirow[t]{2}{*}{ MIDPxBIWdeg } & & & & 0.000 & & & \\
\hline & & & & $(0.000)$ & & & \\
\hline \multirow[t]{2}{*}{ BIWevc } & & & & & & -0.002 & \\
\hline & & & & & & $(0.002)$ & \\
\hline \multirow[t]{2}{*}{ MIDPxBIWevc } & & & & & & 0.000 & \\
\hline & & & & & & $(0.000)$ & \\
\hline Log-likelihood & -349.1621 & & & -348.696 & & -348.256 & \\
\hline AIC & 724.3243 & & & 723.391 & & 722.512 & \\
\hline BIC & 775.6147 & & & 774.682 & & 773.803 & \\
\hline HQC & 744.6724 & & & 743.739 & & 742.860 & \\
\hline
\end{tabular}

Note. The table presents the estimated coefficient of the OLS Model using centrality measures. Variable descriptions are provided in the Table1. The probability of being outside the safe harbour is individually regressed over the betweenness, degree, eigenvector centrality measures, respectively in Model (1), (2) and (3), with a series of control variables as described in Section 3.3. *, **, and *** denote significance at the $10 \%, 5 \%$, and $1 \%$ levels, respectively. Standard errors are reported in parentheses.

\section{Copyrights}

Copyright for this article is retained by the author(s), with first publication rights granted to the journal.

This is an open-access article distributed under the terms and conditions of the Creative Commons Attribution license (http://creativecommons.org/licenses/by/4.0/). 